\title{
Pure versus guided mirror exposure to reduce body dissatisfaction: a preliminary study with university women
}

Citation for published version (APA):

Moreno-Dominguez, S., Rodriguez-Ruiz, S., Fernandez-Santaella, M. C., Jansen, A. T. M., \& TuschenCaffier, B. (2012). Pure versus guided mirror exposure to reduce body dissatisfaction: a preliminary study with university women. Body Image, 9(2), 285-288. https://doi.org/10.1016/j.bodyim.2011.12.001

Document status and date:

Published: 01/03/2012

DOI:

10.1016/j.bodyim.2011.12.001

Document Version:

Publisher's PDF, also known as Version of record

\section{Document license:}

Taverne

Please check the document version of this publication:

- A submitted manuscript is the version of the article upon submission and before peer-review. There can be important differences between the submitted version and the official published version of record.

People interested in the research are advised to contact the author for the final version of the publication, or visit the DOI to the publisher's website.

- The final author version and the galley proof are versions of the publication after peer review.

- The final published version features the final layout of the paper including the volume, issue and page numbers.

Link to publication

\footnotetext{
General rights rights.

- You may freely distribute the URL identifying the publication in the public portal. please follow below link for the End User Agreement:

www.umlib.nl/taverne-license

Take down policy

If you believe that this document breaches copyright please contact us at:

repository@maastrichtuniversity.nl

providing details and we will investigate your claim.
}

Copyright and moral rights for the publications made accessible in the public portal are retained by the authors and/or other copyright owners and it is a condition of accessing publications that users recognise and abide by the legal requirements associated with these

- Users may download and print one copy of any publication from the public portal for the purpose of private study or research.

- You may not further distribute the material or use it for any profit-making activity or commercial gain

If the publication is distributed under the terms of Article $25 \mathrm{fa}$ of the Dutch Copyright Act, indicated by the "Taverne" license above, 
Brief research report

\title{
Pure versus guided mirror exposure to reduce body dissatisfaction: A preliminary study with university women
}

\author{
Silvia Moreno-Domínguez ${ }^{\mathrm{a}, *}$, Sonia Rodríguez-Ruiz ${ }^{\mathrm{b}}, \mathrm{M}^{a}{ }^{a}$ Carmen Fernández-Santaellab ${ }^{\mathrm{b}}$, \\ Anita Jansen ${ }^{\mathrm{c}}$, Brunna Tuschen-Caffier ${ }^{\mathrm{d}}$ \\ a Dept. of Psychology, Faculty of Humanities and Educational Sciences, Campus Las Lagunillas, s/n, University of Jaén, 23071 Jaén, Spain \\ b Dept. of Personality, Assessment and Psychological Treatment, Faculty of Psychology, Campus La Cartuja s/n, Granada, Spain \\ ' Dept. of Clinical Psychological Science, Faculty of Psychology, Maastricht University, P.O. Box 616, 6200 MD Maastricht, The Netherlands \\ ${ }^{\mathrm{d}}$ Albert Ludwigs University of Freiburg, Institute of Psychology, Engelbergerstrasse 41, D-79106 Freiburg, Germany
}

\section{A R T I C L E I N F O}

\section{Article history:}

Received 3 February 2011

Received in revised form 4 December 2011

Accepted 5 December 2011

\section{Keywords:}

Body dissatisfaction

Mirror exposure

Imagery exposure

Extinction

University women

\begin{abstract}
A B S T R A C T
While effectiveness of mirror exposure to reduce body dissatisfaction has been demonstrated, the exposure was almost always combined with other interventions. The aim of the study was to evaluate the effectiveness of a pure mirror exposure intervention compared with a guided mirror exposure (participants are guided to describe their body shape in a non-evaluative manner) and an imagery exposure intervention (participants are guided to describe their body through mental representation). Thirty-one women with high body dissatisfaction received five sessions of treatment under one of the three conditions. All interventions reduced body dissatisfaction, but only the mirror exposures successfully reduced the frequency of negative thoughts and feelings of ugliness. Pure mirror exposure was more effective than guided exposure for reducing body discomfort within and between sessions. Pure mirror exposure, based on the traditional extinction paradigm, led to strong emotional activation followed by a fast decrease in emotional reactivity.
\end{abstract}

(c) 2011 Elsevier Ltd. All rights reserved.

\section{Introduction}

Body exposure (i.e., asking individuals to stand repeatedly and for prolonged periods in front of a mirror) is a central component of body image therapy and has been shown to reduced body image disturbance and avoidance behaviors in women with and without eating disordered symptoms (Delinsky \& Wilson, 2006). Key, George, Beattie, Stammers, Lacey, and Waller (2002) compared two conditions of body image treatment within an inpatient program for anorexia nervosa. Only the treatment including mirror confrontation produced significant and sustained improvement in body dissatisfaction, reducing body anxiety and avoidance behaviors. Similarly, Delinsky and Wilson (2006) reported that a mindfulness-based adaptation of mirror exposure therapy resulted in significant improvements in body image disturbance compared with a non-directive body image treatment. Also, a new body exposure plus neutral description technique has been shown as

\footnotetext{
* Corresponding author at: Department of Psychology, Facultad de Humanidades y CCEE, Edif. C-5, 116, Campus de las Lagunillas, s/n, Universidad de Jaén, 23071 Jaén, Spain. Tel.: +34 95321 3372; fax: +34 953211881

E-mail addresses: smoreno@ujaen.es (S. Moreno-Domínguez), srruiz@ugr.es (S. Rodríguez-Ruiz), mcfersan@ugr.es (M.C. Fernández-Santaella), a.jansen@maastrichtuniversity.nl (A. Jansen), tuschen@psychologie.uni-freiburg.de (B. Tuschen-Caffier)
}

a promising strategy to reduce body dissatisfaction. Participants are asked to describe their physical appearance in a detailed, neutral way using a mirror or video technique. By describing one's body as precisely and as neutrally as possible, negative evaluations, such as "I am a fat nobody," were de-emphasized. This body exposure plus neutral description technique decreased body dissatisfaction in overweight adults and negative feelings concerning their body among individuals with binge eating disorder (Hilbert, Tuschen-Caffier, \& Vögele, 2002) and increased body satisfaction and decreased anxiety in obese adolescents (Jansen, Bollen, Tuschen-Caffier, Roefs, Tanghe, \& Braet, 2008). These data indicate that the body exposure without negative thinking led to the extinction of negative feelings.

To answer the question of whether cognitive restructuring is crucial for producing changes in body satisfaction, the aim of the present study was to compare the effectiveness of the body exposure plus neutral description technique with exposure without neutral description (pure mirror exposure). We dismantled the body exposure plus neutral description technique (Hilbert et al., 2002) by comparing three types of exposure interventions: pure mirror exposure, guided mirror exposure, and imagery (nonmirror) exposure. It was hypothesized that both mirror exposure interventions would be more successful for reducing body image disturbance than the non-mirror exposure intervention. It has been argued that exposure therapy involves a powerful negative 
emotional experience and leads to the extinction of the negative feelings by preventing escape from that affect (Key et al., 2002). Therefore, it was assumed that pure mirror exposure, based on the traditional extinction model of anxiety responses, would be as effective as guided mirror exposure for reducing body image disturbance.

\section{Method}

\section{Participants}

Thirty-one university women from southern Spain participated in this study. They were recruited through advertisements placed throughout the university campus asking for women with body dissatisfaction who were interested in receiving an experimental psychological treatment. In a screening session, they were informed about the study purpose, weighed, and measured. All three groups received the same initial description of the study purpose (any participant knew that the specific purpose of the study was to determine whether mirror exposure was superior to nonmirror exposure intervention). Participants were semi-randomly assigned to one of the three exposure interventions according to BMI. Then, they were briefly interviewed (for exclusion criteria) and asked to complete the Body Shape Questionnaire (BSQ; Cooper, Taylor, Cooper, \& Fairburn, 1987) and the Eating Attitude Test (EAT; Garner, Olmsted, Bohr, \& Garfinkel, 1982). Participants were excluded if they had (a) BSQ scores $<105$ and EAT scores $>30$ (to select women without substantial eating disordered symptoms), (b) a body mass index (BMI) $<20$ or $>28$ (to make sure that their body dissatisfaction was not due to extremes in body size) and (c) were currently following a weight loss program (to ensure that changes in body dissatisfaction were not due to changes in body weight). All participants received a detailed description of the intervention for each exposure condition $(n=10$, pure mirror exposure condition; $n=10$, guided mirror exposure condition; and $n=11$, imagery exposure condition). The groups did not differ in age $(M=20.12, S D=1.76)$ or $\mathrm{BMI}(M=24, S D=2.83)$.

\section{Psychological Measures}

The Eating Attitude Test (Garner et al., 1982) is a 40-item instrument used to assess a broad range of eating disorder symptoms. Cut-offs of 30 and 50 characterize at-risk and clinical populations, respectively (Mintz \& O'Halloran, 2000). In the present study, the Spanish version of EAT was used (Castro, Toro, Salamero, \& Guimera, 1991). The alpha was .98 in this study.

The Body Shape Questionnaire (Cooper et al., 1987) is a 34-item questionnaire assessing body image concerns. The clinical cut-off is 105. Also the Spanish version of BSQ was used (Raich, Mora, Soler, Avila, Clos, \& Zapater, 1996). The alpha across all administrations ranged from .80 to .94 in this study.

The Thoughts Checklist (TCL; Cooper \& Fairburn, 1992) was made up of self-statements chosen to be typical of the thoughts individuals with eating disorders might have while completing the mirror confrontation task. The TCL includes 16 negative items rated by the frequency of occurrence ( 1 = thought did not occur to $6=$ thought was there all the time). For each of the three conditions, a mean of the negative cognitions score was computed. The alpha across all administrations ranged from .78 to .80 in this study.

A visual analogue scale (VAS) was used to measure the dimension of beauty versus ugliness. The word beauty was located at the left side of the scale, and the word ugly was at the right. The participants marked the line between the words according to their feelings of beauty and ugliness. A score of zero was given for the beauty extreme and a score of 100 for the ugly extreme.
A subjective discomfort scale (SDS) was used to assess the level of discomfort felt by participants during the sessions. Participants rated their feeling at the beginning of the session and every $5 \mathrm{~min}$ during the session using a scale from 1 (no discomfort at all) to 10 (maximum discomfort).

\section{Procedure}

Before the treatment sessions started, participants individually completed all of the self-report measures. Under the two mirror exposure conditions, they were given beige colored underwear to wear for each treatment session. All participants received five exposure sessions for $40 \mathrm{~min}$ twice a week. Afterwards, participants again completed all measures, except the EAT, and were weighed. One month later, follow-up data from the questionnaires were collected.

Participants under the two mirror exposure conditions were instructed to stand at a distance of two feet in front of the mirror. In the pure mirror exposure intervention, they were asked to look freely at their entire body and pay attention to their feelings and thoughts. They were asked to be completely focused on their body and to try not to relieve the discomfort caused by this exercise. Participants spoke aloud during the session so the researchers could monitor whether participants were focused on trouble body areas. Participants in the guided mirror exposure intervention also stood in front of the mirror and were asked to describe themselves as precisely as they could by answering questions that were asked to them by the therapist from the exposure manual (TuschenCaffier \& Florin, 2002; Tuschen-Caffier, Pook, \& Frank, 2001). The procedure comprised questions designed to enhance the attention focused on specific body areas, such as the head, upper and lower body, legs, arms and feet (e.g., "What do your eyes look like?"). Participants in the guided imagery exposure intervention had to describe their body through the mental representation of their body with the same protocol as the guided mirror exposure intervention; however, they were not in front of a mirror and did not wear the underwear. Body discomfort throughout the sessions was measured using the SDS.

\section{Statistical Analyses}

Statistical analyses of BSQ, TCL, and VAS were based on $3 \times 3$ repeated measures ANOVAs with Intervention as a betweensubjects factor (pure vs. guided vs. imagery) and Time as a within-subjects factor (pre-intervention, post-intervention, 1month follow-up). SCS during the sessions was analyzed by a $3 \times(5 \times 10)$ repeated measures ANOVA with Intervention as the between-subjects factor and Sessions (5) and Measures (10: 1 baseline and 9 measures throughout each session) as the withinsubjects factors. The Greenhouse-Geisser epsilon correction was applied. Results are reported with size effect $\left(\eta p^{2}\right)$ and statistical power $(1-\beta)$. Post hoc tests were performed using the $t$ statistic. The level of significance was set at .05 for all analyses.

\section{Results}

Table 1 shows the means (and standard deviations) for body dissatisfaction, negative thoughts, and beauty-ugliness as a function of intervention phase and group. No significant differences were found on these measures at the pre-intervention phase.

\section{Body Dissatisfaction}

ANOVA results revealed a significant main effect of Time, $F(2,56)=37.56, p<001, \eta p^{2}=.57,1-\beta=1.00$, and a significant Intervention $\times$ Time interaction, $F(4,56)=2.68, p<.05, \eta p^{2}=.16$, 
Table 1

Means and standard deviations of measures in each intervention group.

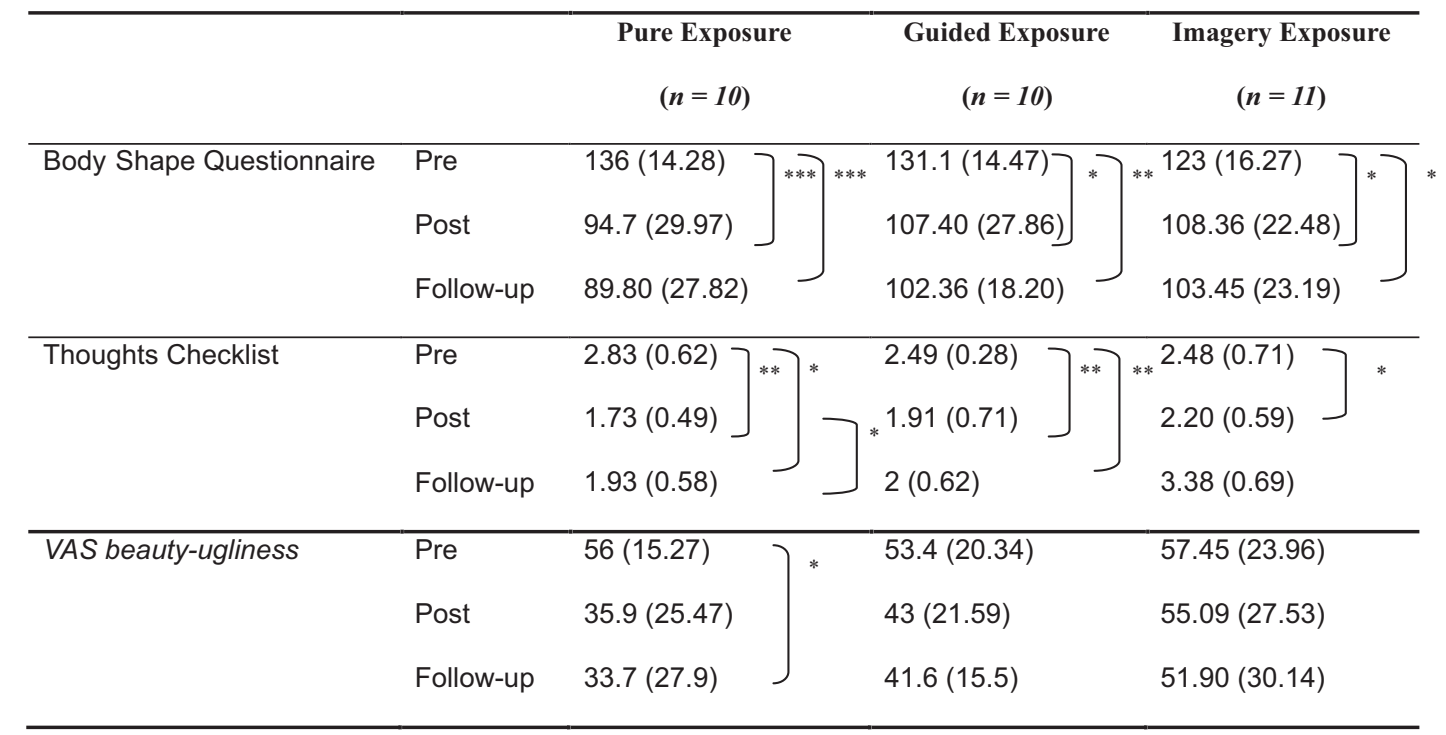

Note. VAS $=$ Visual Analogue Scale. ${ }^{*} p<.05 ;{ }^{* *} p<.01 ;{ }^{* * *} p<.001$.

$1-\beta=.71$. The three groups showed significant reductions from pre-intervention to post-intervention and follow-up, but the differences were larger for pure mirror exposure than for guided mirror exposure and imagery exposure groups (see Table 1). Post hoc comparisons of the changes from pre-intervention revealed significant group differences between pure mirror and imagery exposure groups at both post-intervention $(p<.03)$ and follow-up $(p<.02)$. The differences between pure mirror and imagery exposure groups were marginally significant at follow-up $(p=.09)$. No other group comparison was significant.

\section{Negative Thoughts}

ANOVA results showed a main effect of Time, $F(2,56)=24.26$, $p<.001, \eta p^{2}=.46,1-\beta=.99$, and a significant Intervention $\times$ Time interaction, $F(4,56)=3.92, p<.02, \eta p^{2}=.22,1-\beta=.78$. As can be seen in Table 1 , only the pure and guided mirror exposure groups showed significant reductions at both post-intervention and follow-up. The imagery exposure group showed a significant reduction just at post-intervention. Post hoc comparisons of the changes from pre-intervention revealed significant group differences only between pure mirror and imagery exposure groups at both post-intervention $(p<.01)$ and follow-up $(p<.01)$. The difference between pure and guided mirror exposure groups was marginally significant at post-intervention $(p=.06)$. No other group comparison was significant.

\section{VAS Beauty-Ugliness}

ANOVA results revealed a main effect of Time, $F(2,56)=7.1$, $p<.05, \eta p^{2}=.20,1-\beta=.87$. The three groups showed a reduction from pre-intervention to post-intervention and follow-up, but only the pure mirror exposure group reached significance from preintervention to follow-up (see Table 1). No other group comparison was significant.

\section{Subjective Discomfort Within and Between Sessions}

Fig. 1a and $\mathrm{b}$ shows the average discomfort data throughout and within sessions as a function of the groups. The Intervention $\times$ Sessions $\times$ Measures ANOVA revealed main effects for
Sessions, $F(4,108)=59.68, p<.001, \eta p^{2}=.69,1-\beta=1.00$, and Measures, $F(9,243)=5.31, p<.05, \eta p^{2}=.16,1-\beta=.93$. There were also significant interaction effects for Intervention $\times$ Sessions, $F(8,108)=8.78, p<.001, \eta p^{2}=.39,1-\beta=1.00$, and Intervention $\times$ Measures, $F(18,243)=3.21, p=.05, \eta p^{2}=.19,1-\beta=.92$.
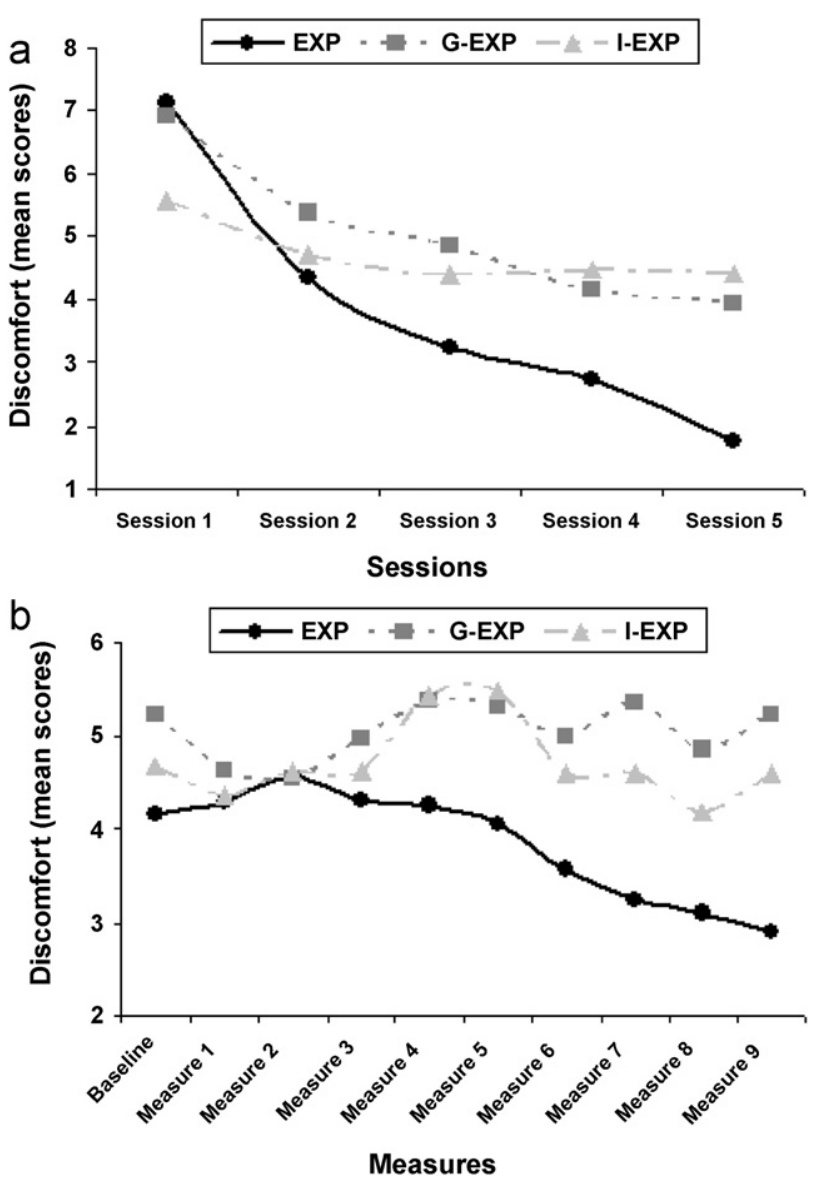

Fig. 1. Means of subjective discomfort (a) between and (b) within sessions as a function of the groups. EXP: pure mirror exposure; G-EXP: guided mirror exposure; I-EXP: imagery (non-mirror) exposure. 
Analysis of the Intervention $\times$ Sessions interaction revealed significant differences between the three groups in the linear trend $(p<.0001)$. As can be seen in Fig. 1a, the pure mirror exposure group had the largest reduction in subjective discomfort throughout the sessions. Differences between pure and guided mirror exposure groups appeared in Sessions $3(p<.04)$ and $5(p<.005)$. Differences between pure mirror and imagery exposure groups appeared in Sessions $4(p<.04)$ and $5(p<.001)$. No significant differences appeared between guided mirror and imagery exposure groups.

Analysis of the Intervention $\times$ Measures interaction revealed significant differences between the three groups in the linear $(p<.03)$ and cubic $(p<.03)$ trends. As can be seen in Fig. 1b, the pure mirror exposure group showed an increase in the first three measures followed by a steady decrease in the last four measures (all $p s<.03$ ). The guided mirror and imagery exposure groups showed significant increase towards the middle of the session (all $p s<.05$ ) followed by a return to the initial level (imagery exposure group) or no return (guided mirror exposure group) by the end of the session.

\section{Discussion}

Our findings indicate that the three interventions significantly reduced body dissatisfaction, but only interventions including mirror confrontation resulted in sustained reduction in the frequency of negative thoughts and/or feelings of ugliness. On the other hand, measures of subjective discomfort within and between the sessions indicate the superiority of the pure mirror exposure intervention in reducing such discomfort compared to the other two interventions. These findings support the hypothesis that pure exposure intervention is successful for reducing body image disturbance.

A fascinating question is why pure mirror exposure was more effective than guided mirror exposure in reducing body image discomfort within sessions. For the guided exposure intervention, the body is the conditioned stimuli, and negative thinking is the unconditioned stimuli leading to negative feelings, such as anxiety and avoidance behavior (Jansen et al., 2008). According to this model, participants exposed to their body with neutral thinking reduce their negative feelings through cognitive restructuring. However, the pure exposure intervention also led to the reduction of negative feelings, and the data suggest that the reduction was faster. Based on the traditional extinction model, it could be argued that pure exposure produces a faster reduction because it does not interfere with the natural flow of expression of the negative feelings. Therefore, pure exposure could be successful in reducing body image disturbance because of the emotional rather than the cognitive response (Key et al., 2002).

Various alternative explanations are possible. Our procedure of having participants responding to the question about the level of body discomfort every 5 min during the therapeutic session can be considered a form of self-reflection and, therefore, can be interpreted as a cognitive intervention. On the other hand, the faster decrease in body discomfort during the sessions in the pure exposure intervention could be interpreted as a form of avoidance (e.g., participants could be avoiding troubled body parts given the non-directional nature of this kind of exposure). However, this explanation seems unlikely as the post-intervention and follow-up measures showed a significant improvement in body dissatisfaction, negative thoughts, and feelings of ugliness.

This was a preliminary study with a very small sample. Therefore, findings should be interpreted with caution until replicated with a larger sample. Additionally, all participants knew that they were being evaluated for a body image treatment and knew the purpose of this study, which could have influenced their responses. In spite of these limitations, the data are promising and support that pure exposure (as is guided exposure) is effective for reducing body image disturbances in a subclinical population. Further investigation is needed to confirm whether pure exposure is also successful at reducing body image disturbances in women with eating disorders and who have BMI under 20 or over 28 .

\section{Acknowledgements}

This research was supported by a grant from the Spanish Ministry of Science and Technology (project PSI2009-08417).

\section{References}

Castro, J., Toro, J., Salamero, M., \& Guimera, E. (1991). The Eating Attitudes Test: Validation of the Spanish version. Evaluación Psicológica, 7, 175-189.

Cooper, M., \& Fairburn, C. F. (1992). Thoughts about eating, weight and shape in anorexia nervosa and bulimia nervosa. Behavior Research and Therapy, 30 501-511.

Cooper, P. J., Taylor, J., Cooper, Z., \& Fairburn, C. G. (1987). The development and validation of the Body Shape Questionnaire. International Journal of Eating Disorders, $6,485-494$.

Delinsky, S. S., \& Wilson, G. T. (2006). Mirror exposure for the treatment of body image disturbance. International Journal of Eating Disorders, 39, 108-116.

Garner, D. M., Olmsted, M. P., Bohr, Y., \& Garfinkel, P. E. (1982). The Eating Attitudes Test: Psychometric features and clinical correlates. Psychological Medicine, 12, 871-878.

Hilbert, A., Tuschen-Caffier, B., \& Vögele, C. (2002). Effects of prolonged repeated body image exposure in binge-eating disorder.Journal of Psychosomatic Research, 52, 137-144.

Jansen, A., Bollen, D., Tuschen-Caffier, B., Roefs, A., Tanghe, A., \& Braet, C. (2008). Mirror exposure reduces body dissatisfaction and anxiety in obese adolescents: A pilot study. Appetite, 51, 214-217.

Key, A., George, C. L., Beattie, D., Stammers, K., Lacey, H., \& Waller, G. (2002). Body image treatment within an inpatient program for anorexia nervosa: The role of mirror exposure in the desensitization process. International Journal of Eating Disorders, 31, 185-190.

Mintz, L. B., \& O'Halloran, M. S. (2000). The Eating Attitudes Test: Validation with DSM-IV eating disorder criteria. Journal of Personality Assessment, 74, 489-503.

Raich, R. M., Mora, M., Soler, A., Avila, C., Clos, I., \& Zapater, L. (1996). Adaptación de un instrumento de evaluación de la insatisfacción corporal. Clínica y Salud, 7 51-66.

Tuschen-Caffier, B., \& Florin, I. (2002). Teufelskreis Bulimie: Ein Manual zur psychologischen Therapie. Goettingen: Hogrefe.

Tuschen-Caffier, B., Pook, M., \& Frank, M. (2001). Evaluation on manual-based cognitive-behavioral therapy for bulimia nervosa in a service setting. Behavior Research and Therapy, 39, 299-308. 